\title{
A Rare Cause of Pigmentation Disorder; Tuberous Sclerosis Complex
}

\author{
Ragip Ismail Engin ${ }^{1}$ and Atilla Cayir ${ }^{2 *}$ \\ ${ }^{1}$ Region Training and Research Hospital, Department of Dermatology, Erzurum, Turkey \\ ${ }^{2}$ Region Training and Research Hospital, Department of Pediatrics, Erzurum, Turkey \\ "Corresponding author: Atilla Cayir, Departments of Pediatrics, Regional Training and Research Hospital, Erzurum, Turkey, Tel:+905331382744; Fax: +04422325090; \\ E-mail: dratillacayir@gmail.com
}

Rec date: June 08, 2015; Acc date: Aug 08, 2015; Published date: Aug 18, 2015

Copyright: $\odot 2015$ Cayir A. This is an open-access article distributed under the terms of the Creative Commons Attribution License, which permits unrestricted use, distribution, and reproduction in any medium, provided the original author and source are credited.

\begin{abstract}
Tuberous sclerosis complex is an autosomal dominant neurocutaneous disease principally characterized by the triad of mental retardation, adenoma sebaceum and epilepsy. It may affect all organs, but most commonly the skin, brain, heart, eyes and kidneys. The earliest finding, and the most common in the skin, consists of hypopigmented macules (ash leaf). In addition, numerous small hypopigmented macules (confetti-like macules) occur in the pretibial region. Shagreen patches, a form of collagenoma, may be seen in the lumbosacral region in half of patients. Skin findings also include angiofibromas, known as adenoma sebaceum, in the face and Koenen's tumor. Other skin lesions include cafe-au-lait spots and molloscum fibrosum pendulum resembling acrochordon. We describe the skin findings in particular of tuberous sclerosis complex in the light of the current literature.
\end{abstract}

Keywords Mutations; Lesions; Protein; Hypopigmented

\section{Introduction}

Tuberous sclerosis complex (TSC) is an autosomal dominant genodermatosis also known as Bourneville's disease and characterized by benign, non-invasive tumor-like lesions [hamartoma] in the brain, skin, kidney, heart and lungs [1]. The incidence ranges between 1/5800 and 1/10,000 [2]. It was first described in 1862 by Von Recklinghausen with autopsy findings in a baby consisting of sclerotic areas in the brain and tumor in the heart. Bourneville first employed the term tuberous sclerosis as a distinct syndrome in 1880 [3]. These first terms are still valid today, but TSC is now preferred with widespread system involvement [4]. Approximately 1 million people of all racial and ethnic origins have been reported to be affected worldwide. The appearance of the disease varies considerably, and diagnosis is generally clinical $[5,6]$. Cutaneous lesions were reported in more than $90 \%$ of cases in a patient series by the Mayo Clinic, cerebral pathology in approximately 90\%, renal anomalies in $70-90 \%$ and retinal hamartoma in approximately 50\% [7]. The classic Vogt triad consisting of facial angiofibroma, mental retardation and resistant epilepsy has been reported in at most $30-40 \%$ of patients [5].

\section{Genetics and Pathophysiology}

TSC is a disease inherited in an autosomal dominant manner. However, it is sporadic in more than two in three cases, resulting from new spontaneous mutations. The first Tuberous Sclerosis Complex Consensus Conference, held by the National Institutes of Health $(\mathrm{NIH})$ in 1998, produced recommendations for the clinical management and diagnosis of patients with TSC. Two genes known to be responsible for cases of TSC were identified at that time, but their functions and molecular roles are still unclear. The disease derives from mutations in the TSC1 gene on chromosome 9q34 and in TSC2 in chromosome 16p13.3. The protein coded by TSC1 is hamartin while the protein coded by TSC2 is tuberin. These proteins constitute a complex triggered by the protein Rhep activated by GTPase. This complex inhibits mammalian target of rapamycin complex 1 (mTORC1). As a result they protect the protein kinase involved in regulation of cell metabolism, migration, growth and differentiation. Mutation in both TSC1 and TSC2 results in loss of mTORC structural and tumor suppressor activities. The hamartomatous lesions in patients with TSC thus result from abnormal cell proliferation and differentiation. Understanding of the functional relations between TSC1/TSC2 and mTORC1 has led to important clinical advances in the use of mTORC1 inhibitors in the treatment of such serious clinical symptoms of TSC as pulmonary lymphangiomatosis (LAM), renal angiomyolipomas and cerebral subependymal giant cell astrocytoma $[6,8]$.

Genotypical variations may be pronounced in genotypically identical individuals. Even minimal correlation between mutations and their clinical outcomes is thought to be capable of causing significant variation in severity and degree of clinical symptoms among members of the same family. In additionally, more severe symptoms occur in patients with mutation in TSC2 compared to TSC1 (including more frequent and severe epilepsy, moderate or severe mental retardation, cortical tubers, renal angiomyolipomas, retinal hamartomas and advanced facial angiofibromas) [6].

\section{Diagnosis}

Diagnosis of TSC is based on clinical criteria. Various changes were introduced to the existing criteria following the latest consensus conference in 2012. These diagnostic criteria are shown in Table 1 [9].

\section{Clinical findings}

TSC exhibits a wide range of clinical findings, both within families and between individuals. Disease findings in women are milder than those in men. Any organ or system may be involved in TSC $[10,11]$. 


\begin{tabular}{|c|c|}
\hline Major criteria & Minor criteria \\
\hline Hypomelanotic macules $(\geq 3$, diameter at least $5 \mathrm{~mm}$ ) & Confetti skin lesions \\
\hline Angiofibromas ( $\geq 3$, or cephalic fibrous plaque) & Dental enamel pitting $(\geq 3)$ \\
\hline Ungual fibromas $(\geq 2)$ & Intraoral fibromas $(\geq 2)$ \\
\hline Shagreen patch & Retinal achromic patch \\
\hline Multiple retinal hamartomas & Multiple renal cysts \\
\hline Cortical dysplasias $(\geq 3)^{*}$ & Non-renal hamartomas \\
\hline \multicolumn{2}{|l|}{ Subependymal nodules } \\
\hline \multicolumn{2}{|l|}{ Subependymal large cell astrocytomas } \\
\hline \multicolumn{2}{|l|}{ Cardiac rhabdomyomas } \\
\hline \multicolumn{2}{|l|}{ Lymphangioleiomyomatosis ${ }^{* \star}$} \\
\hline \multicolumn{2}{|l|}{ Angiomyolipomas $(\geq 2)^{* *}$} \\
\hline $\begin{array}{l}\text { Definitive diagnosis: presence of } 2 \text { major criteria } \\
\text { Probable diagnosis: } 1 \text { major } \\
1 \text { major and } 1 \text { minor } \\
\geq 2 \text { minor criteria }\end{array}$ & $\begin{array}{l}\text { * Tubers and cerebral white matter radial migration lines included }{ }^{* *} \text { Presence of } \\
\text { lymphangioleiomyomatosis or angiomyolipomas alone is not sufficient for definitive } \\
\text { diagnosis }\end{array}$ \\
\hline
\end{tabular}

Table 1: TSC diagnostic criteria.

\section{Dermatological findings}

Skin findings are seen in almost $100 \%$ of individuals with TSC. These include hypomelanotic macules (87-100\%), facial angiofibromas (47-90\%), shagreen patch (2-80\%), fibrous facial plaque and ungual fibromas [17-87\%]. The skin lesions most responsible for impairing appearance are facial angiofibromas. However, no cutaneous lesions lead to any serious health problem [12].

The earliest and most common cutaneous finding in TSC is hypopigmented macules [95-98\%]. These appear at birth or in infancy. Lesions are off-white in color, $1-3 \mathrm{~cm}$ in size and may be polygonal or oval in shape. Since they typically resemble the ash tree lead they are known as ash leaf lesions. In addition, large numbers of hypopigmented macules may be observed, particularly in the pretibial region. These are known as confetti macules [13,14]. Under a Wood lamp, Ash leaf lesions appear as hypopigmented lesions lighter in color than the normal skin [15]. Since 1-2 white macules may also be observed in normal healthy individuals, TSC should be considered in the presence of 3 or more highly hypopigmented macules identified at birth [16].

Adenoma sebaceum (AS) is also known as facial angiofibroma and is the most characteristic cutaneous finding in TSC. It is seen in approximately $75 \%$ of patients, generally between the ages of 3 and 10 . It is rare at birth or in babyhood, but increases in number and size up to puberty, after which it remains stable. It may be seen in the nasolabial region, cheek, nose and jaw, and sometimes on the forehead and in hairy skin. Symmetrically located bright red telengiactatic papules, $1-10 \mathrm{~mm}$ in size with a hard, flat surface are observed. Lesions may sometimes grow and assume the form of a cauliflower-like mass $[17,18]$.
Shagreen patches, a form of collagenoma located in the lumbosacral area, are seen in $50 \%$ of patients and occur in the first 10 years of life. These are solitary, soft plaques, the color of skin or a yellowish color, with irregular margins, raised above the skin and of varying sizes. Lesions with large follicular pores may resemble orange peel in appearance $[19,20]$.

Periungual fibromas, also known as Koenen's tumor, are generally asymptomatic, hard, flat, horny, skin-colored tumors, 5-10 $\mathrm{mm}$ in size in the folds of the finger and toe nails. They are connective tissue hamartomas that form in the bed or folds of the nail. These are commonly seen in women aged 15-29 and more frequently in the toe nails. They may be subungually located and lead to onycholysis and are seen in approximately $50 \%$ of patients with TSC [21].

Fibrous plaques on the forehead or in hairy skin may be regarded as a variant of the shagreen patch. These are hard, reddish-brown fibromatous plaques of various shapes and sizes. Histopathologically, they are similar to angiofibroma. They are seen in $20 \%$ of patients [22].

Other cutaneous lesions are rare, but can assist with diagnosis. These include cafe-au-lait spots and molloscum fibrosum pendulum resembling acrochordon and are located in the neck and axillar and inguinal regions. In contrast to neurofibromatosis, café-au-lait spots in cases of TSC have no neurofibromas or axillar freckling [20,22]. Groups of hypopigmented hairs, known as poliosis, may sometimes be seen. Fibrous nodules may be seen in the oral mucosa in $10 \%$ of patients. These are most common in the gingiva and palate. Pitting in the dental enamel is widespread in adult patients. Diffuse hyperpigmentation, hemangiomas resembling nevus flammeus and soft-pedicled fibromas in the neck and axillar area may also develop [23]. 


\section{Central Nervous System (CNS)}

Tumors of the CNS are the major cause of the mortality and morbidity in TSC. Differentiation of TSC cerebral lesions, including subependymal nodules, cortical tubers and subependymal giant cell astrocytomas is possible using neuroimaging. Subependymal nodules are seen in $90 \%$ of cases and cortical and subcortical tubers in $70 \%$. Subependymal giant cell astrocytomas may be present in $6-14 \%$ of all cases of TSC. These giant cell astrocytomas may grow, causing pressure and obstruction, and thus lead to significant morbidity and mortality

Seizures are reported to be seen in more than $80 \%$ of individuals with TSC. This may reflect bias in cases with more severe involvement. TSC is one of the known causes of infantile spasm/hypsarrythmia. Developmental or mental retardation may be present in at least $50 \%$ of cases. Complications of severe mental retardation are one of the leading causes of premature death among individuals with TSC (such as status epilepticus or bronchopneumonia). Individuals with TSC are at serious risk in terms of neurodevelopmental and behavioral development. The most commonly seen behavioral and psychiatric diseases are part of autism spectrum diseases. Hyperactivity or attention deficit hyperactivity disease and aggression are commonly seen in patients with TSC $[12,25]$.

\section{Kidneys}

Renal involvement is the second most common cause of early death in individuals with TSC. Definable renal lesions are reported to be seen in an average of $80 \%$ of children with TSC $[26,27]$. Five different types of renal lesion may be observed; benign angiomyolipoma (70\%) epithelial cyst (20-30\%), oncocytoma (benign adenomatous hamartoma, $<1 \%)$, malign angiomyolipoma $(<1 \%)$ and renal cell carcinoma $(<3 \%)[28,29]$.

Benign angiomyolipomas consist of abnormal blood vessels, smooth muscle layer and mature adipose tissue. They tend to grow in size and number in children. Benign angiomyolipomas may lead to life-threatening bleeding, renal parenchymal changes and end stage renal failure. Renal cysts contain hypertrophic, hyperplastic eosinophilic cells. Some patients may have both TSC1 and autosomal dominant polycystic kidney disease type 1 findings. Progressive cyst growth in these cases may cause end stage renal failure by compressing the functional parenchyma [30]

Malign angiomyolipoma and renal cell carcinoma may result in mortality. Although these two tumors are rare, they are still more common than in the general population. Renal cell carcinoma has been reported in $2-5 \%$ of cases of TSC. Age at diagnosis of renal cell carcinoma in patients with TSC is $28-30$ years earlier than sporadic cases $[31,32]$.

\section{The Heart}

Cardiac rhabdomyomas are seen in $47-67 \%$ of cases. These tumors have been documented to gradually decrease in size and finally resolve entirely. Cardiac rhabdomyomas are frequently widest in the neonatal period [33].

\section{The Lungs}

Pulmonary lymphangiomatosis (LAM), primary seen in women, is observed in approximately $30 \%$ of individuals with TSC, and is 5 times more prevalent than sporadic LAM. Respiratory difficulty and hemoptysis may be seen in individuals with sporadic LAM. A diffuse reticular pattern pay be present at thoracic radiography and diffuse interstitial changes at CT. Pneumothorax or chylothorax may occur. Respiratory failure and death may occur in some individuals. The clinical course of TSC-related LAM and pulmonary cysts is milder compared to sporadic examples.

\section{The Eye}

Retinal lesions of TSC are hamartomas (elevated mulberry lesions or plaque-like lesions) and achromic patches (resembling hypopigmented cutaneous lesions). One or more of these lesions may be seen in $75 \%$ of affected individuals. Although these lesions are generally asymptomatic, they may proceed with total exudative retinal detachment and progressively growing retinal astrocytic hamartomas with neovascular glaucoma [35].

\section{Extrarenal angiomyolipoma (AML)}

Although rare, cases have been reported. One retrospective study reported hepatic AML in 62 patients with TSC [36]. In addition, neuroendocrine tumors (NETs) such as pituitary adenoma ACTHoma and GHoma], parathyroid adenoma and hyperplasia and pancreatic adenomas insulinoma and islet cell adenoma] may also be seen in individuals with TSC. Recent single-case reports have also described gastrinoma, pheochromacytoma and carcinoids [37].

\section{Management}

The following factors set out by the Clinical Issues Panel at the Tuberous Sclerosis Consensus Conference held in June 1998 are recommended for the purpose of determining severity of disease in individuals diagnosed with TSC [38]:

- Medical history, particularly in terms of findings of TSC

- Family history, particularly in terms of findings of TSC

- Physical examination in a dark chamber using a Woods lamp, and particularly in terms of dermatological findings

- Cranial CT/MRI

- Renal ultrasonography

- Ophthalmic examination

- Electrocardiography and echocardiography in the presence of cardiac symptoms

- Neurodevelopmental and behavioral evaluation

- Thoracic CT for young females

- Medical genetic consultation

Treatment of Clinical Symptoms:

Dermabrasion, cryosurgery, curettage, chemical peeling, electrodessication, excision and laser therapies have recently been reported to be capable of use in the treatment of angiofibroma or other cutaneous. However, repeat treatments may be necessary due to the self-renewing properties of lesions [39].

Subependymal giant cell astrocytomas can be treated medically with FDA-approved mTOR inhibitors when growing giant cell 
astrocytomas are diagnosed early. These mTOR inhibitors reduce the need for several neurosurgical procedures [40].

Early control of seizures is thought to reduce and prevent subsequent epileptic encephalopathy. The effects of different treatments for infantile spasm may vary among individuals. One study reported that vigabatrin is effective in $73 \%$ of infantile spasm in children with TSC. Even multiple anticonvulsants may fail to bring seizures under control in some cases, however [41].

In terms of renal angiomyolipomas, several authors have reported that the most significant indicator of potential bleeding and need for intervention is a tumor diameter greater than $3.5-4 \mathrm{~cm}$. Prophylactic embolization or renal surgery (enucleation or partial nephrectomy) can be performed for large symptomatic angiomyolipomas exceeding $3.5-4 \mathrm{~cm}$ in diameter [42].

Since LAM is seen almost exclusively in women it has been suggested that estrogen stimulates the smooth muscle cells in the lung. Medroxyprogesterone and/or oophorectomy exhibit therapeutic effects in the great majority of patients by reducing estrogen release. Oxygen therapy is required in patients with pulmonary failure. Lung transplantation may be necessary in severe conditions [43].

\section{Surveillance}

The following routine observations are recommended for individuals with TSC [12]:

- Cranial CT/MRI once every year or 3 years for asymptomatic children or young adults, and once every 5 years for asymptomatic adults

\section{Renal imaging}

Once every 1-3 years for individuals with no previously determined renal lesions

Monthly ultrasonography for individuals with angiomyolipomas smaller than $3.5-4 \mathrm{~cm}$

Renal CT/MRI in the presence of renal tumors growing in numbers or size

- Electroencephalography for seizure management

- Neurodevelopmental and behavioral evaluation at various times

- Echocardiography in the presence of cardiac symptoms

\section{Pulmonary evaluation}

High resolution CT (HRCT) at least once in all women with TSC after the age of 18

Routine pulmonary function tests at 6-12 month intervals and HRCT every 1-3 years in the presence of symptoms and other clinical findings

\section{Conclusion}

TSC is a genetic disease capable of producing various symptoms and causing severe complications. Early identification of cases and diagnosis is therefore very important. Early diagnosis is important in terms of informing families about the disease and of regular monitoring of these children. This will also facilitate treatment and avert potential complications.

\section{References}

1. Moavero R, Coniglio A, Garaci F, Curatolo P (2013) Is mTOR inhibition a systemic treatment for tuberous sclerosis? Ital J Pediatr 39: 57.

2. Somoano B, Tsao H (2008) Genodermatoses with cutaneous tumors and internal malignancies. Dermatol Clin 26: 69-87i.

3. Hanno R, Beck R (1987) Tuberous sclerosis. Neurol Clin 5: 351-360

4. Gomez MR (1996) Neurocutaneous Disease. Neurology in Clinical Practice. (2nd Edn), Butterworth Heinemann, USA.

5. Franz DN, Bissler JJ, McCormack FX (2010) Tuberous sclerosis complex: neurological, renal and pulmonary manifestations. Neuropediatrics 41: 199-208.

6. Rabito MJ, Kaye AD (2014) Tuberous sclerosis complex: perioperative considerations. Ochsner J 14: 229-239.

7. Curatolo P, Bombardieri R, Jozwiak S (2008) Tuberous sclerosis. Lancet 372: 657-668.

8. Krueger DA, Northrup H (2013) International Tuberous Sclerosis Complex Consensus Group. Tuberous sclerosis complex surveillance and management: recommendations of the 2012 International Tuberous Sclerosis Complex Consensus Conference. Pediatr Neurol 49: 255-265.

9. Northrup H, Krueger DA (2013) Tuberous sclerosis complex diagnostic criteria update: recommendations of the 2012 international tuberous sclerosis complex consensus conference. Pediatr Neurol 49: 243- 254.

10. Au KS, Williams AT, Roach ES, Batchelor L, Sparagana SP, et al. (2007) Genotype/phenotype correlation in 325 individuals referred for a diagnosis of tuberous sclerosis complex in the United States. Genet Med 9: $88-100$.

11. Sancak O, Nellist M, Goedbloed M, Elfferich P, Wouters C, et al. (2005) Mutational analysis of the TSC1 and TSC2 genes in a diagnostic setting: genotype--phenotype correlations and comparison of diagnostic DNA techniques in Tuberous Sclerosis Complex. Eur J Hum Genet 13: 731741.

12. Northrup H, Koenig MK, Au KS (1999) Tuberous Sclerosis Complex. Tuberous Sclerosis Complex .

13. Rosser T, Panigrahy A, McClintock W (2006) The diverse clinical manifestations of tuberous sclerosis complex: a review. Semin Pediatr Neurol 13: 27-36.

14. Crino PB, Nathanson KL, Henske EP (2006) The tuberous sclerosis complex. N Engl J Med 355: 1345-1356.

15. Harper JI (1998) Tuberous sclerosis complex:Textbook of Dermatology. (6thedn), Blackwell Science, United Kingdom.

16. http://www.emedicine.com/derm/topic438.htm

17. Morris BS, Garg A, Jadhav PJ (2002) Tuberous sclerosis: a presentation of less-commonly encountered stigmata. Australas Radiol 46: 426-430.

18. Odom RB, James WD, Berger TG. Tuberous sclerosis (Epiloia Bourdneville's disease). (9thedn), WB Saunders Company, Philadelphia, USA.

19. Rosser T, Panigrahy A, McClintock W (2006) The diverse clinical manifestations of tuberous sclerosis complex: a review. Semin Pediatr Neurol 13: 27-36.

20. Evans SE (2013) Malignite ile iliskili genodermatozlar. Turkderm 47: 103-110.

21. Curatolo P, Bombardieri R, Jozwiak S (2008) Tuberous sclerosis. Lancet 372: 657-668.

22. Lin AN, Carter DM (1992) Tuberous sclerosis. (3rdedn), W.B.Saunders Company, Philadelphia, USA.

23. Tepe B, Özcan H, Seyhan M (2007) Tuberoz skleroz kompleksi, iki olgu sunumu. Inönü Üniversitesi Tip Fakültesi Dergisi 14: 123-127.

24. Torres OA, Roach ES, Delgado MR, Sparagana SP, Sheffield E, et al. (1998) Early diagnosis of subependymal giant cell astrocytoma in patients with tuberous sclerosis. J Child Neurol 13: 173-177.

25. Baker P, Piven J, Sato Y (1998) Autism and tuberous sclerosis complex: prevalence and clinical features. J Autism Dev Disord 28: 279-285. 
Citation: Engin RI and Cayir A (2015) A Rare Cause of Pigmentation Disorder; Tuberous Sclerosis Complex. Pigmentary Disorders 2: 211. doi:

26. Ewalt DH, Sheffield E, Sparagana SP, Delgado MR, Roach ES (1998) Renal lesion growth in children with tuberous sclerosis complex. J Urol 160: 141-145.

27. Dixon BP, Hulbert JC, Bissler JJ (2011) Tuberous sclerosis complex renal disease. Nephron Exp Nephrol 118: e15-20.

28. Sancak O, Nellist M, Goedbloed M, Elfferich P, Wouters C, et al. (2005) Mutational analysis of the TSC1 and TSC2 genes in a diagnostic setting: genotype--phenotype correlations and comparison of diagnostic DNA techniques in Tuberous Sclerosis Complex. Eur J Hum Genet 13 731-741.

29. Patel U, Simpson E, Kingswood JC, Saggar-Malik AK (2005) Tuberose sclerosis complex: analysis of growth rates aids differentiation of renal cell carcinoma from atypical or minimal-fatcontaining angiomyolipoma. Clin Radiol 60: 665-673.

30. Martignoni G, Bonetti F, Pea M, Tardanico R, Brunelli M, et al. (2002) Renal disease in adults with TSC2/PKD1 contiguous gene syndrome. Am J Surg Pathol 26: 198-205.

31. Pea M, Bonetti F, Martignoni G, Henske EP, Manfrin E, et al. (1998) Apparent renal cell carcinomas in tuberous sclerosis are heterogeneous: the identification of malignant epithelioid angiomyolipoma. Am J Surg Pathol 22: 180-187.

32. Borkowska J, Schwartz RA, Kotulska K, Jozwiak S (2011) Tuberous sclerosis complex: tumors and tumorigenesis. Int J Dermatol 50: 13-20.

33. Dabora SL, Jozwiak S, Franz DN, Roberts PS, Nieto A et al. (2001) Mutational analysis in a cohort of 224 tuberous sclerosis patients indicates increased severity of TSC2, compared with TSC1, disease in multiple organs. Am J Hum Genet 68: 64-80.

34. McCormack FX (2008) Lymphangioleiomyomatosis: a clinical update. Chest 133: 507-516.
35. Shields JA, Eagle RC Jr, Shields CL, Marr BP (2004) Aggressive retinal astrocytomas in four patients with tuberous sclerosis complex. Trans Am Ophthalmol Soc 102: 139-147.

36. Fricke BL, Donnelly LF, Casper KA, Bissler JJ (2004) Frequency and imaging appearance of hepatic angiomyolipomas in pediatric and adult patients with tuberous sclerosis. AJR Am J Roentgenol 182: 1027-1030.

37. Dworakowska D, Grossman AB (2009) Are neuroendocrine tumours a feature of tuberous sclerosis? A systematic review. Endocr Relat Cancer 16: 45-58.

38. Roach ES, Sparagana SP (2004) Diagnosis of tuberous sclerosis complex. J Child Neurol 19: 643-649.

39. Franz DN (2013) Everolimus in the treatment of subependymal giant cell astrocytomas, angiomyolipomas, and pulmonary and skin lesions associated with tuberous sclerosis complex. Biologics 7: 211-221.

40. Franz DN, Leonard J, Tudor C, Chuck G, Care M, et al. (2006) Rapamycin causes regression of astrocytomas in tuberous sclerosis complex. Ann Neurol 59: 490-498.

41. Camposano SE, Major P, Halpern E, Thiele EA (2008) Vigabatrin in the treatment of childhood epilepsy: a retrospective chart review of efficacy and safety profile. Epilepsia 49: 1186-1191.

42. van Baal JG, Smits NJ, Keeman JN, Lindhout D, Verhoef S (1994) The evolution of renal angiomyolipomas in patients with tuberous sclerosis. J Urol 152: 35-38.

43. McCormack FX, Inoue Y, Moss J, Singer LG, Strange C, et al. (2011) Efficacy and safety of sirolimus in lymphangioleiomyomatosis. $\mathrm{N}$ Engl J Med 364: 1595-1606. 